\title{
Faculty Experiences On Emergency Remote Teaching During Covid-19: A Multicentre Qualitative Analysis
}

\author{
Blessy Prabha Valsaraj ${ }^{1}$, Bhakti More ${ }^{2}$, Seena Biju ${ }^{3}$, Payini Valsaraj ${ }^{4}$, Vinod Pallath ${ }^{5}$ \\ Sultan Qaboos University
}

\begin{abstract}
Purpose: During COVID 19 pandemic Emergency Remote Teaching (ERT) in Higher Education emerged and faculty members had to go through a transformation in teaching-learning without preparedness. The purpose of the study was to understand the instructional delivery experiences of faculty members, explore the challenges and how they overcame those challenges during the transition from traditional classroom teaching to ERT.
\end{abstract}

Design/methodology/approach: A qualitative research approach using phenomenology was adapted for the study. The study was conducted in selected renowned government and private universities offering professional education in India, Malaysia, Oman, and United Arab Emirates. Data analysis was done using NVivo, data management software, based on Ricouer's theory of interpretation.

Findings: The findings identified unique challenges and opportunities in faculty experiences during the implementation of ERT and universities require more preparedness in implementing a revised pedagogy. Addressing these unique challenges is, therefore, essential in effective change management and ensuring the effectiveness of instructional delivery.

Research limitations/implications: The study comprises faculty experiences from only selected countries (United Arab Emirates, Oman, India, and Malaysia) and disciplines such as Business Studies, Design and Architecture, Engineering, Hospitality and Tourism Management, Medicine, and Nursing. The research contributes towards change management and adaptability strategies during emergency transitions.

Social implications: The study aims to understand the social context and human experiences in the process of ERT and their impact on the process of learning.

Originality/value: The findings of the study would throw light into the factors influencing the paradigm shift in the pedagogy for present and future higher education.

Keywords: Higher Education, COVID-19, Emergency Remote Learning, Online learning, faculty experiences. 